\title{
DOUBLE INFERIOR VENA CAVA: A RARE CASE REPORT
}

\author{
Ganpat Singh Choudhary1, Mohan Lal Bishnoi², Awdesh Kumar Sharma ${ }^{3}$
}

${ }^{1}$ Associate Professor, Department of General Surgery, Dr. S.N. Medical College, Jodhpur.

${ }^{2}$ Consultant Surgeon, Jodhpur.

${ }^{3}$ Assistant Professor, Department of General Surgery, Dr. S.N. Medical College, Jodhpur.

\section{ABSTRACT}

A case of double Inferior Vena Cava (IVC), where left sided IVC is of the dimensions of normal IVC. Double IVC, as such, is a rare anomaly. It occurs in $0.2-0.5 \%$ of cases. Left sided IVC is reported where right IVC is absent. What makes our case unusual is that both right and left IVC were seen. The right IVC being normal, the left IVC is probably due to persistence of left supracardinal vein (Infrarenal segment), which normally disappears. The conglomeration of such vascular malformations is of immense surgical importance, specially is indicative of a grossly defective angiogenesis. Though the etiology may be unknown yet there may be the role of certain teratogenic agents on angiogenic cell clusters (differentiated from mesoderm of the wall of the yolk sac at the beginning of 3rd week of intrauterine life).(1,2)

\section{KEYWORDS}

Inferior Vena Cava, Supracardinal Vein, Angiogenic Cell Cluster.

HOW TO CITE THIS ARTICLE: Choudhary GS, Bishnoi ML, Sharma AK. "Double inferior vena cava: a rare case report.” J Evolution Med Dent Sci 2016;5(4):266-269, DOI: 10.14260/jemds/2016/56

\section{INTRODUCTION}

Congenital anomalies of the Inferior venecava are a relatively rare pathology and are incidentally found in an asymptomatic patient. From biopics material their incidence has been estimated to be $2-3 \%$ and the percentage of intraoperative findings varies in different series between $0.2-0.5 \%$ of various kinds of anomalies, caval duplication and a left positioned vena cava are the most commonly found.(3)

Anomalies of the Inferior Vena Cava (IVC) and its tributaries have been known to anatomists since 1793, when Abernethy.(4) described a congenital mesocaval shunt and azygos continuation of the IVC in a 10-month-old infant with polysplenia and dextrocardia. Since the development of crosssectional imaging, congenital anomalies of the IVC and its tributaries have become more frequently encountered in asymptomatic patients. Vascular structures are usually readily identified on Computed Tomographic (CT) scans of the abdomen and pelvis obtained with intravenously administered contrast material.

However, use of intravenous contrast material is occasionally contraindicated. In addition, with helical acquisition, the venous structures may be imaged during the arterial phase, when little or no contrast material is present in the veins. Therefore, familiarity with these variations is essential for correct interpretation of cross-sectional images, to avoid erroneous diagnosis of retroperitoneal and mediastinal masses or adenopathy and to alert the surgeon and angiographer of potential sources of complications preoperatively.(5)

Here, we present a case of vena caval duplication (Left sided IVC probably due to a persistent left supracardinal vein) with normal tributaries to main IVC.

Financial or Other, Competing Interest: None.

Submission 27-10-2015, Peer Review 28-10-2015,

Acceptance 24-11-2015, Published 14-01-2016.

Corresponding Author:

Dr. Ganpat Singh Choudhary,

1-C, Kudi Road,

Krisna Nagar,

Jodhpur.

E-mail: drganpatsingh@gmail.com

DOI:10.14260/jemds/2015/56

\section{CASE REPORT}

A 32-year-old male patient, chronic alcoholic, presented to the Emergency Department with lump in the epigastrium, jaundice, high grade fever, vomiting. Upon investigation he had leucocytosis, hypoalbuminemia, normal coagulation profile. USG showed multiple space occupying lesions in both lobes of liver. Further CECT abdomen was done which showed multiple abscesses, it also showed duplication of IVC on the left side which extended from left internal iliac vein, extending superiorly on left lateral aspect of aorta draining in left renal vein. In the meanwhile the patient was managed by a suprapubic balloon catheter for liver abscess.

As part of further investigation for the double IVC, the patient underwent CT angiogram. CT angiogram revealed continuation of iliac vessels upwards up to the level of left renal vein s/o duplication of infra renal part of IVC. However, suprarenal part of IVC was normal.

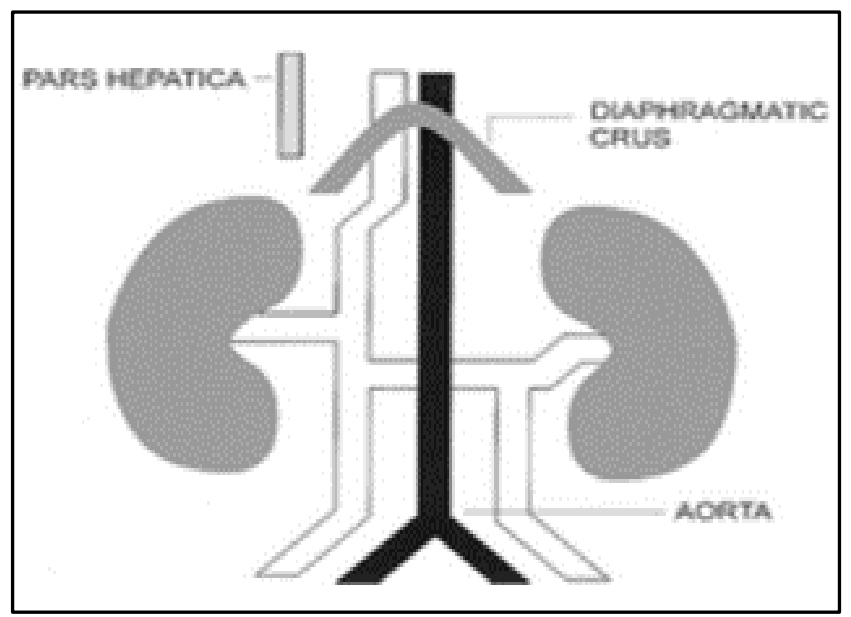

Diagrammatic Representation of Double IVC 

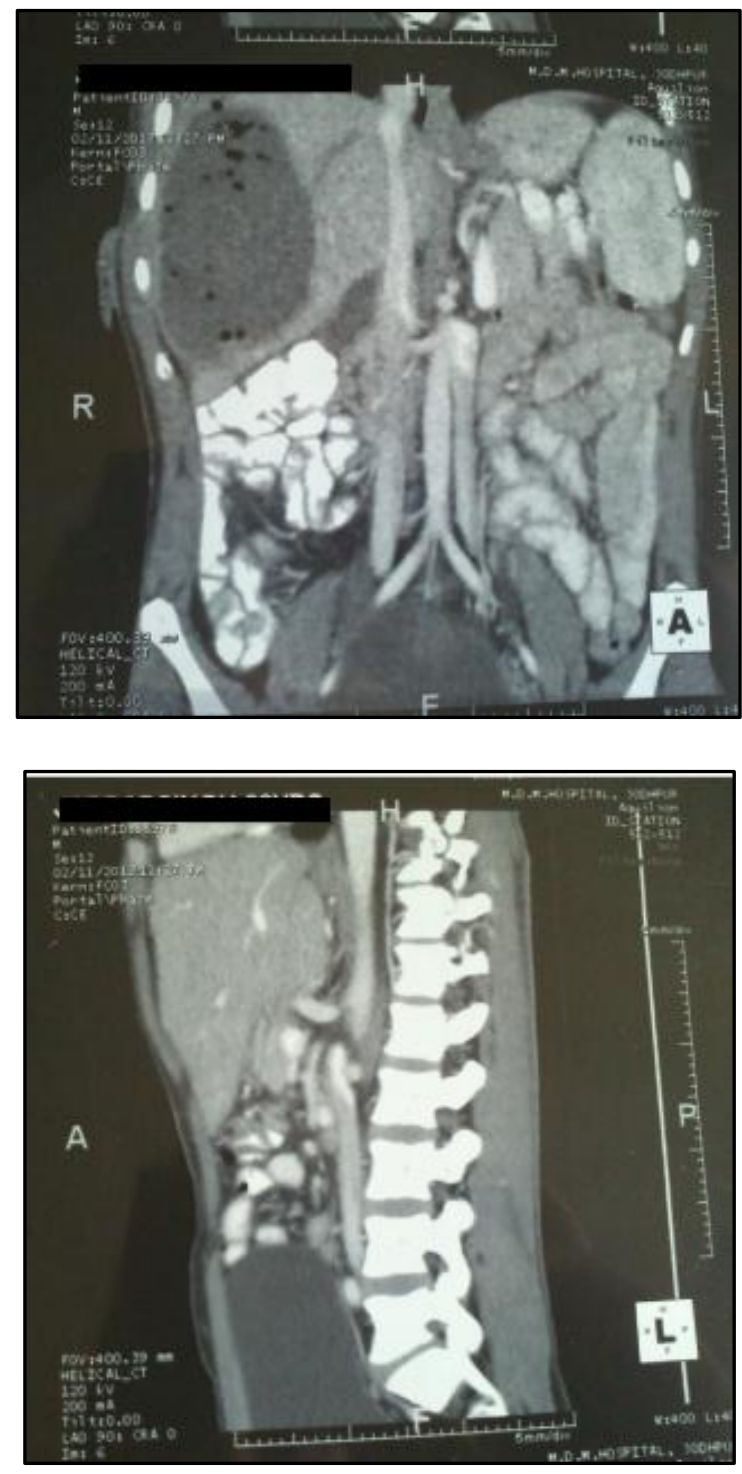

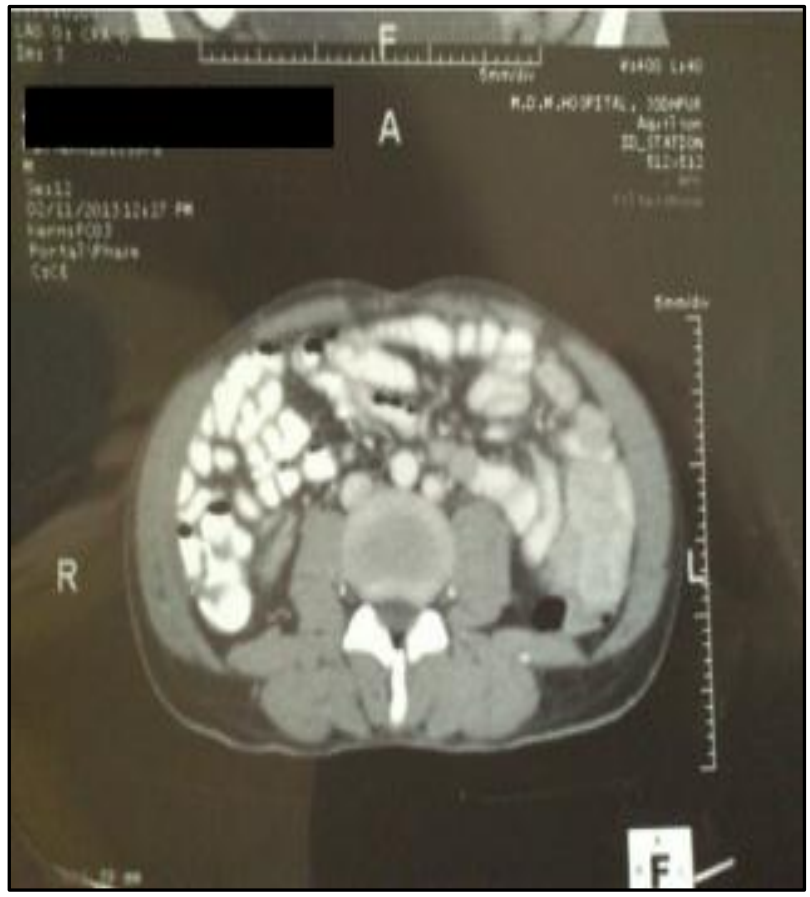

\section{DISCUSSION}

Normal IVC develops from.(6)

1. The lowest part of right posterior cardinal vein (Sacral segment).

2. Right supracardinal vein (Post renal segment) receives 3rd and 4th lumbar veins.

3. Right supra-subcardinal anastomosis (Renal segment), receives renal and gonadal veins.

4. Right subcardinal vein (Prerenal segment) receives right suprarenal vein.

5. Right vitelline vein (Hepatic segment).

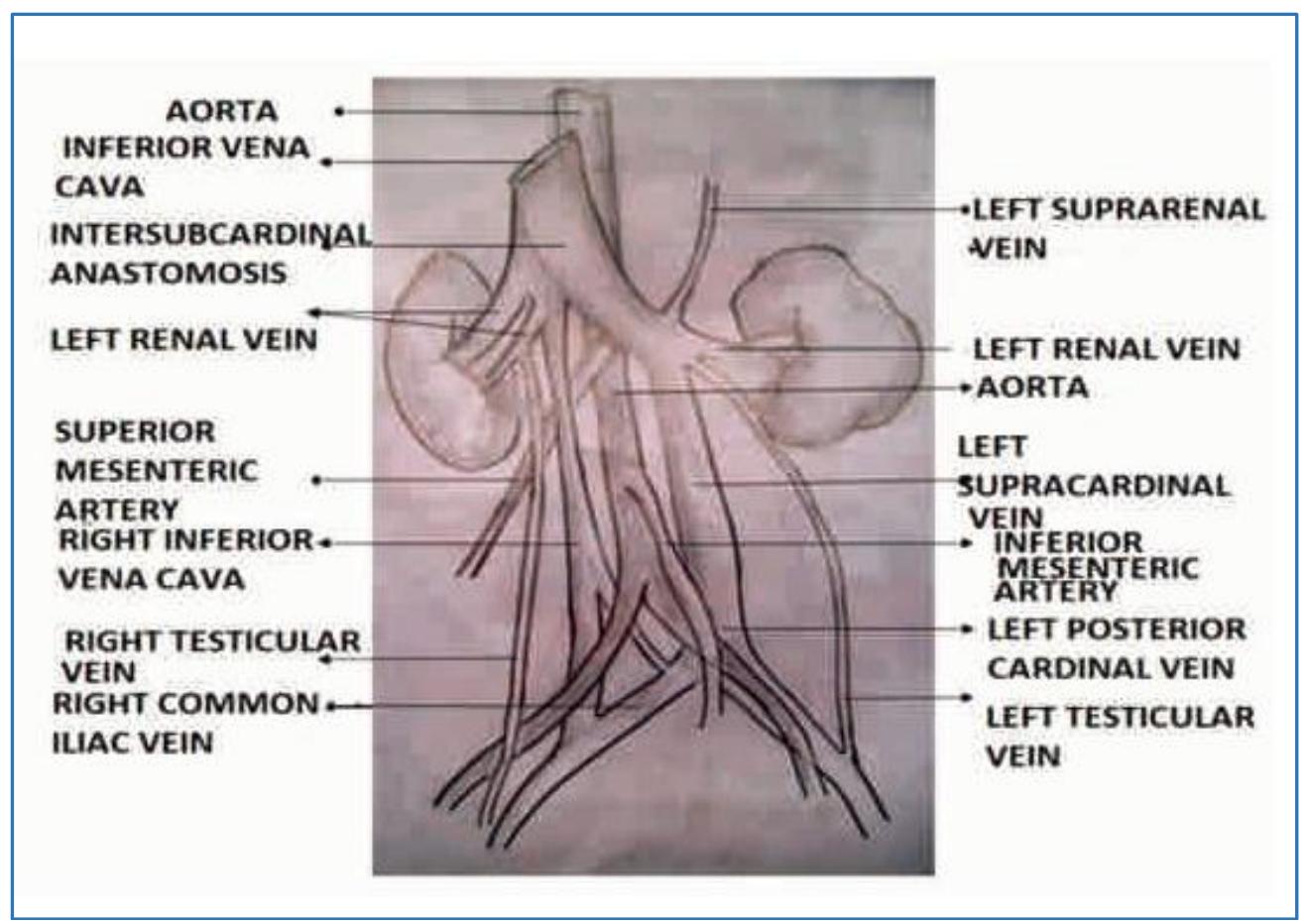

Diagrammatic Representation of Double IVC 


\section{EMBRIOLOGICAL EXPLANATION OF DOUBLE IVC}

The formation of the inferior vena cava is a complex event that has been well described. It is formed between the sixth and eighth weeks of embryonic development via a series of anastomoses and regressions of the following primitive trunk veins: posterior cardinal veins, subcardinal veins and supracardinal veins. The prerenal segment is derived from the right subcardinal vein, while the renal segment is derived via anastomoses between the subcardinal and supracardinal veins, and the postrenal segment is derived from the right supracardinal vein.(7)

Unfortunately, patients are diagnosed during exploration of various symptoms via imaging tests that do not always provide a complete visualization of the abdominal veins. The most detailed descriptions are typically from anatomical studies of cadavers dissected during medical school anatomy courses. The chart shows the types of variations reported by various authors and their classification under the system Natsis, Apostolidis, Noussios et al. (2010) have proposed for duplication of the inferior vena cava.

The literature strongly suggests that the non-regression of the left supracardinal vein during embryonic development leads to the occurrence of a second abdominal vessel, which is generally positioned to the left of the aorta in adults. As shown by Natsis, Apostolidis, Noussios et al. (2010); however, the configuration of this supernumerary vessel and thus its embryonic origin is quite variable. These authors have proposed that duplications of the inferior vena cava be classified as complete or incomplete.

Where complete, the most likely etiological cause is the persistence of the left suprasubcardinal anastomosis of the postsubcardinal anastomosis, and probably of the intersubcardinal anastomosis, which in turn results in the persistence of the left supracardinal vein. Such a case may also be associated with an absence of iliac anastomosis (Posterior distal intercardinal anastomosis). In cases of incomplete duplication, in which the supernumerary vena cava to the left is smaller and sometimes irregular, the likely cause is inadequate regression of the supracardinal vein.

Although, it is an invasive procedure, phlebography is indicated by several authors (ZUBAIR, HASHMI and SMAROFF, 2007) as the gold standard for diagnosing duplication of the inferior vena cava. Other authors have suggested that the combination of ultrasound and CT are sufficient for an adequate diagnosis. However, Evans, Earis and Curtis (2001) reported misdiagnosis and unnecessary intervention in a patient following the use of these tests.

\section{Classification Described In Literature}
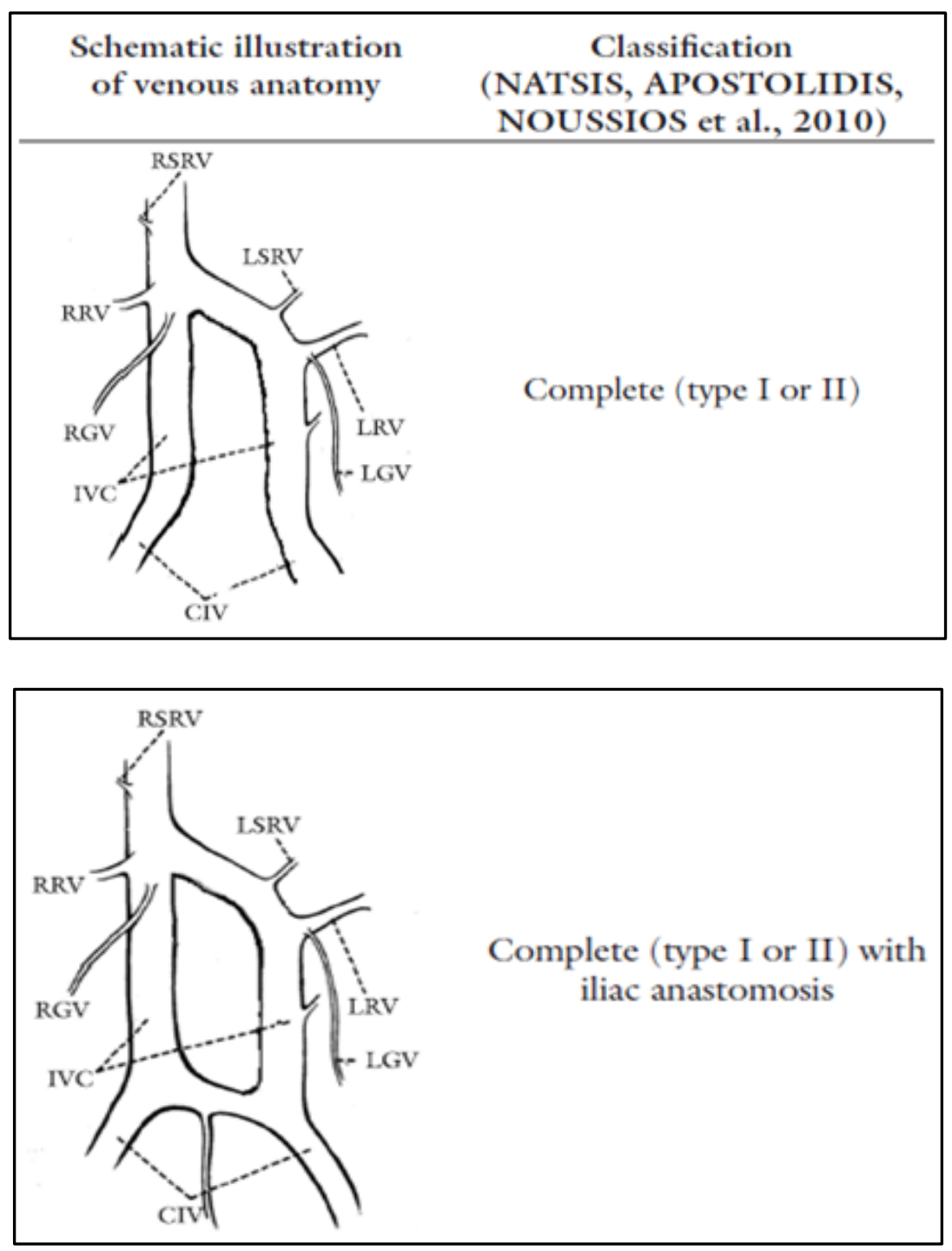

RSRV-Right supra-renal vein; LSRV-Left supra-renal vein; RRV-Right renal vein; LRV-Left renal vein; RGV-Right gonadal vein; LGV-Left gonadal vein; IVC-Inferior vena cava; CIV-Common iliac vein. 


\section{CONCLUSION}

Anatomical descriptions in the literature reveal great variation in the duplication of the inferior vena cava, and a higher incidence of 'incomplete' duplication. Persistence of left supracardinal and subcardinal veins in fetal life have resulted in the formation of left IVC of the size of the normal right IVC. Persistence of right supracardinal and subcardinal veins have resulted in formation of right IVC of much smaller dimensions. Above the renal veins, IVC was normal and in its usual position.(8)

Understanding this variation is important in the clinical realm, both for avoiding misdiagnosis of retroperitoneal illnesses and for facilitating procedures to prevent PTE in patients with DVT who cannot be medicated with anticoagulants. (9) Anatomical variation of this kind should be studied via imaging tests such as phlebography that are capable of both identifying such variants and revealing the anatomy of the relevant vessels.

Though the etiology may be unknown yet there may be the role of certain teratogenic agents or angiogenic cell clusters (Differentiated from visceral mesoderm of the wall of the yolk sac) at the beginning of 3rd week of intrauterine life.(10)

Double IVC has importance in resection of abdominal aortic aneurysm.(11) If the left IVC is quite small, it may not present any difficulty in Aortic resection. If it is the case of only left IVC and if it goes anterior to aorta, right renal vein can be divided, provided right adrenal and gonadal veins open into it. The possible presence of this vessel is of surgical significance during left lumbar sympathectomy because it may conceal the sympathetic trunk.

\section{REFERENCES}

1. Abernethy J. Account of two instances of uncommon formation in the viscera of the human body. Philos Trans R Soc 1793;83:59-66.
2. Cossu ML, Ruggiiu M, Fais E, Sparta C, Dettori G, Noya, G; (2000): Title not available Minerva Chir 55(10):703-8. (Article In Italian).

3. Giordano JM, Trout HH, (1986): Anomalies of inferior vena cava; Journal of Vascular Surgery. 3(6):924-83. Hans SS, Gordon M; (1989): Double inferior vena cava \& abdominal aortic aneurysm. Journal of Cardiovascular Surgery. 26(I):76-8.

4. Koch FR, Bouwer AJ, Bornman MS, et al. (1986): Anomalies of inferior vena cava South African Medical Journal. 69(I):69-70.

5. Larde D, Frijol J, Belloir C, et al. (1981): Contribution of computed tomography to the exploration of congenital anomalies of inferior vena cava; Journal of Radiology 62(6-7);363-7.

6. Sardi A, Minken SL, (1987): The placement of intracaval filters in an anomalous (Left sided) vena cava; Journal of Vascular Surgery 6(1):84-6.

7. Williams PL, Bannister H, Berry MM, Collins P, Dyson M, Dussek JE, et al. Gray's Anatomy In: Embryology and Development. 38th Edn, Churchill Livingstone. London: 324-5 (1995).

8. Palit S, Deb S. A rare presentation of double inferior vena cava with anomalous pattern of azygos and hemiazygos venous systems: A case report; J Anat Soc India 51(1):6567, (2002).

9. Williams P, Warwick. Gray's anatomy. Churchill Livingston England; 2000;36:666.

10. McGregor AL. A synopsis of surgical anatomy. South Africa - Bristol:Wright 1986;12:266-7.

11. Sadler TW. Langman's medical embryology. Lippincott Williams \& Wilkins; India 2006;9:266. 